\title{
sciendo
}

Current Issues in Pharmacy and Medical Sciences

Formerly ANNALES UNIVERSITATIS MARIAE CURIE-SKIODOWSKA, SECTIO DDD, PHARMACIA

journal homepage: http://www.curipms.umlub.pl/

\section{Influence of ketotifen and conventional antiepileptic drugs on the exploratory and spontaneous locomotor activity in mice}

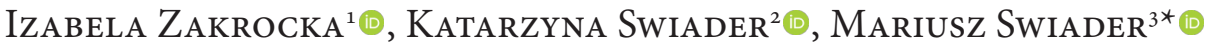

\author{
${ }^{1}$ Department of Nephrology, Medical University of Lublin, Poland \\ ${ }^{2}$ Department of Applied Pharmacy, Medical University of Lublin, Poland \\ ${ }^{3}$ Department of Experimental and Clinical Pharmacology, Medical University of Lublin, Poland
}

\section{ARTICLE INFO \\ Received 01 October 2019 \\ Accepted 30 June 2020}

\section{Keywords:}

locomotor activity,

ketotifen,

antiepileptic drugs.

\begin{abstract}
Drug interactions are major problems in polytherapy, especially in epilepsy, and inappropriate drug selection may result in increased frequency of seizures.

In this study, the influence of histamine type $1\left(\mathrm{H}_{1}\right)$ receptor antagonist ketotifen and four chosen antiepileptic drugs (AEDs) on mice activity was examined. We evaluated three parameters of locomotor activity in mice: horizontal total activity with total distance and vertical activity, as well as animal spontaneous activity. Experiments were divided into two 15-minutes studies. During the first 15 minutes, we examined exploratory activity in mice; in the second period, spontaneous activity was tested. In the experiment, Ketotifen or vehicle were administered once or for 7 days daily, whereas AEDs were given only once before test performance.

Our results show that ketotifen given alone once or for 7 days significantly increased exploratory locomotor activity in mice without affecting their spontaneous activity. However, in combination with AEDs, ketotifen given once or for 7 days differently affected spontaneous and locomotor activity in mice. Our study indicates that the combination of ketotifen with AEDs needs special attention in pharmacotherapy of epilepsy.
\end{abstract}

\section{INTRODUCTION}

Epilepsy is a chronic medical condition defined as recurrent seizure attacks, quite often unprovoked [1]. The prevalence of active epilepsy is estimated between 4 and 10 per 1000 people in the general population [2]. Importantly, the risk of relapse after first unprovoked seizure attack ranges between $23 \%$ and $71 \%$ [3]. Results of studies concerning prognosis of patients with epilepsy remain elusive. Apart from etiology, the effectiveness of epilepsy treatment is considered as the strongest predictor of patients' prognosis. Most researchers highlight that inappropriate treatment significantly reduces patient survival, especially in the mechanism of a sudden unexpected death in epilepsy (SUDEP) [4]. Due to possible refractory course of epilepsy changes in AED administration, drug interactions should be carefully considered in every patient [5].

Histamine is known to affect the central nervous system [6]. It activates four types of histamine receptors $(\mathrm{H}): \mathrm{H}_{1}$, $\mathrm{H}_{2}, \mathrm{H}_{3}$ and $\mathrm{H}_{4}$ [7]. First generational $\mathrm{H}_{1}$ receptor antagonists were found to easily cross the blood-brain barrier and

\footnotetext{
* Corresponding author

e-mail: mariusz.swiader@umlub.pl
}

induce sedation, whereas the $\mathrm{H}_{3}$ receptor is a presynaptic autoreceptor and it belongs to the G-protein coupled receptors (GPCR) [8]. Presynaptic $\mathrm{H}_{3}$ receptors, which are found in hypothalamus, take part in the regulation of histamine release from neurons [8]. Furthermore, $\mathrm{H}_{3}$ receptors may function as heteroreceptors. These modulate the levels of neurotransmitters such as dopamine, acetylcholine, norepinephrine, serotonin, $\gamma$-aminobutyric acid (GABA) and glutamate [9]. Some studies have shown that $\mathrm{H}_{3}$ receptor antagonists also improve cognitive functions in animals. Administration of $12.5 \mathrm{mg} / \mathrm{kg}$ or $25 \mathrm{mg} / \mathrm{kg}$ of thioperamide ( $\mathrm{H}_{3}$ receptor antagonist), for example, increases locomotor activity in mice [10]. In another study, 4-[3-[4-[Piperidinyl]but-1-ynyl]benzyl]morpholine dihydrochloride (JNJ10181457), a $\mathrm{H}_{3}$ antagonist, was found to elevate locomotor activity and anxiety-like behaviors in mice [11].

The role of histamine in convulsive activity inhibition was also previously reported $[12,13]$. Some studies $[14,15]$ have shown that stimulation of histamine receptors by elevating histamine concentration prevents seizures. Still, according to these observations, the first generation of $\mathrm{H}_{1}$ antagonists seems to show opposite effects, and available 
clinical studies have reported that $\mathrm{H}_{1}$-antagonists can induce seizures in children [16] and adults with epilepsy [17].

The influence of ketotifen on convulsive activity in animals was demonstrated in prior work. Herein, ketotifen was discovered to antagonize the effect of histamine and 2-thizolythylamine, inhibitors of pentylenetetrazol-inducted seizures [18]. Another study reported that ketotifen may cause West syndrome or infantile spasm in neonates [19]. Moreover, ketotifen when given to treat rhinitis in children with secondary generalized epilepsy, increased seizure frequency [20]. However, a study analyzing the influence of ketotifen on anticonvulsant activity of AEDs against maximal electroshock seizures (MES) in mice revealed that ketotifen given once increased the anticonvulsant action of carbamazepine (CBZ) and phenobarbital (PB). Furthermore, when ketotifen was given for 7 days, it was noted to reduce the anticonvulsant action of CBZ [21].

The goal of the present study was to examine the effect of ketotifen and AEDs given once or for 7 days on spontaneous and exploratory locomotor activity in mice.

\section{MATERIALS AND METHODS}

\section{Animals}

Adult Swiss mice weighing between 22 and $26 \mathrm{~g}$ (age 7 weeks) were used in this study. Animals were purchased from a licensed breeder (Doctor T. Gorzkowska, Warsaw, Poland). The temperature of air in the laboratory was $23 \pm 2^{\circ} \mathrm{C}$ and natural light-dark cycle was ensured. The mice were kept in colony cages with free access to food and tap water. Adaptation to laboratory conditions lasted for 7 days. After the adaptation time, experimental groups were created, each group consisting of 12 animals. Each mouse was used only once in the experimental procedures. Local Ethics Committee of Lublin approved experimental procedures in this study.

\section{Drugs}

In this study, we used a $\mathrm{H}_{1}$ - receptor antagonist - ketotifen (Sigma, St Louis, MO, USA) and four AEDs - carbamazepine (CBZ; Amizepin, Polfa, Warsaw, Poland), magnesium valproate (VPA; Dipromal, Polfa Rzeszów, Poland), phenobarbital sodium (PB; Luminalum Natrium, Polfa, Warsaw, Poland) and diphenylhydantoin (DPH; Phenytoinum, Polfa, Warsaw, Poland).

Two of the four AEDs - VPA and PB - were dissolved in distilled water. The rest of the tested drugs were suspended in a $1 \%$ solution of Tween 80 (Sigma Louis, MO, USA). All AEDs were given in a dose that was effective against MES, according to previous studies.

All drugs were administered according to a time schedule defined by Świąder et al. [22]. VPA and CBZ were given $30 \mathrm{~min}$ prior to the test, ketotifen and PB $60 \mathrm{~min}$ before the test and DPH $120 \mathrm{~min}$ prior to the test. Ketotifen (1 or 7 days of administration) and single dose of one from examined AEDs were administered at the time prior to tests described above. All drugs were given intraperitoneally in a volume of $0.01 \mathrm{ml} / \mathrm{g}$.

\section{Locomotor activity}

Tests were conducted on a Digiscan Animal Activity Monitor System (Omnitech Electronics, Columbus, OH, USA) according to Łuszczki et al. [23]. The device consisted of an open field box $41 \times 41 \times 32 \mathrm{~cm}$ made of Plexiglas. The open field box was divided into four quadrants by acrylic dividers. Each quadrant measured $20 \times 20 \times 32 \mathrm{~cm}$. Within the box, photobeam emitters were located horizontally every $2.5 \mathrm{~cm}$ and vertically every $4.5 \mathrm{~cm}$, while photocell receivers were located opposite. In the device, movement activated the photocells.

The open field box was divided into four quadrants by acrylic dividers. Each quadrant measured $20 \times 20 \times 32 \mathrm{~cm}$. Data were collected on the computer by Digiscan analyzer, then were recorded and analyzed by an IBM-PC compatible computer. The frequency of collecting data was $100 \mathrm{~Hz}$. To decode movements separately, the time between every other beam activation lasted at least 1 second.

The device collected three kinds of data: horizontal activity (such as total distance) and total activity plus vertical movement (the number of separate photobeam activations caused by the moving animal breaking the photobeam emissions whether horizontally or vertically, respectively).

\section{Procedures}

Experimental groups consisted of 12 animals (in total 168 animals were tested). Before testing, the mice were placed in the chamber to habituate to the procedure. The same conditions were kept the day after. Animals did not receive food for 24 hours before the test. Drugs were given at doses equal to their median effective dose $\left(\mathrm{ED}_{50}\right)$, and were administered according to a time scheduled by Świąder et al. [22]. After intraperitoneal drug administration, the mice were transferred to the activity chamber in which tests were performed twice every 15 minutes. During the examination, two mice were put in the box, opposite to each other. In the first 15 minutes, the animals' exploratory activity was examined; during the subsequent 15 minutes, their spontaneous activity was assessed.

\section{Treatment protocol}

During this study, the effects of ketotifen after single and 7 days administration were assessed. First, every mouse was injected once with ketotifen and one of the tested AED. In the second 'chronic' part of the experiment, after 7 days of ketotifen or vehicle administration, AEDs were given before the test as per [22]. The animals were placed into two groups - the control group (12 animals) - who were given 1\% Tween 80 solution (6 days), the ketotifen group - who were given ketotifen ( 6 days). On the $7^{\text {th }}$ day, both groups received one of the tested AEDs and vehicle or ketotifen. During the 7 days of administration, every mouse was injected once a day between 8.00 and $10.00 \mathrm{am}$. The peak of anticonvulsant activity of ketotifen was determined experimentally.

\section{Statistics}

The Kruskal-Wallis test, followed by Dunn's test were used to statistically verify the results presented in this study. 


\section{RESULTS}

\section{Effect of ketotifen given alone or with AED on locomotor activity in mice after single administration}

\section{Results of exploratory activity examination}

Ketotifen given alone significantly increased animal total and vertical activity (Table 1). From the tested AEDs, CBZ and DPH did not affect mice locomotor activity, while VPA significantly increased total distance, whereas PB significantly increased all examined locomotor activities (Table 1).

CBZ in a dose $7.9 \mathrm{mg} / \mathrm{kg}$ co-administered with ketotifen (dose $4.0 \mathrm{mg} / \mathrm{kg}$ ) significantly decreased animal total distance and vertical activity (Table 1). VPA given in a dose of $234 \mathrm{mg} / \mathrm{kg}$ together with ketotifen significantly lowered mice horizontal (total activity and total distance) and vertical activity (Table 1). Similarly, PB given at a dose of $20.8 \mathrm{mg} / \mathrm{kg}$ with ketotifen significantly decreased mice locomotor activity (all three parameters) compared to PB administered alone (in a dose $24.9 \mathrm{mg} / \mathrm{kg}$. In addition, DPH (dose 7.8 $\mathrm{mg} / \mathrm{kg}$ ) in combination with ketotifen decreased all tested parameters of mice exploratory locomotor activity.

Table 1. Influence of ketotifen (1 day treatment) on exploratory locomotor activity in mice

\begin{tabular}{|l|c|c|c|}
\hline \multirow{2}{*}{ Drugs } & \multicolumn{2}{|c|}{ Horizontal activity } & \multirow{2}{*}{$\begin{array}{l}\text { Vertical } \\
\text { activity }\end{array}$} \\
\cline { 2 - 3 } & Total activity & $\begin{array}{c}\text { Total distance } \\
\text { (cm) }\end{array}$ & \\
\hline Control & $1561 \pm 105$ & $689 \pm 62$ & $232 \pm 32$ \\
Ketotifen [4.0] & $2133 \pm 197 *$ & $816 \pm 84$ & $458 \pm 49 * *$ \\
CBZ [13.4] & $1726 \pm 159$ & $770 \pm 67$ & $198 \pm 35$ \\
CBZ [7.9] & $1547 \pm 83$ & $813 \pm 56$ & $398 \pm 46 * *$ \\
CBZ [7.9]+Ketotifen [4.0] & $1299 \pm 142$ & $444 \pm 52^{*} ; \# \#$ & $178 \pm 21 \# \#$ \\
VPA [254] & $1635 \pm 123$ & $1360 \pm 118 * *$ & $309 \pm 19$ \\
VPA [234] & $1864 \pm 178$ & $1455 \pm 137 * *$ & $342 \pm 24 *$ \\
VPA [234]+Ketotifen [4.0] & $1003 \pm 74 * * ; \# \#$ & $827 \pm 65 \# \#$ & $91 \pm 14 * * ; \# \#$ \\
PB [24.9] & $3109 \pm 205^{* *}$ & $2125 \pm 224 * *$ & $513 \pm 54 * *$ \\
PB [20.8] & $3174 \pm 268 * *$ & $2193 \pm 253 * *$ & $521 \pm 51 * *$ \\
PB [20.8]+Ketotifen [4.0] & $1821 \pm 177 \# \#$ & $1240 \pm 145 * * ;$ & $259 \pm 37 \# \#$ \\
DPH [8.2] & $1862 \pm 137$ & $801 \pm 64$ & $290 \pm 38$ \\
DPH [7.8] & $1547 \pm 83 * *$ & $1083 \pm 54 * *$ & $411 \pm 47 *$ \\
DPH [7.8]+Ketotifen [4.0] & $1625 \pm 133 \#$ & $726 \pm 86 \# \#$ & $175 \pm 20 \# \#$ \\
\hline
\end{tabular}

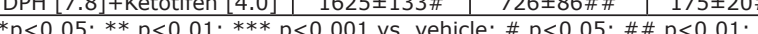

\#\#\# $\mathrm{p}<0.001$ vs. drug. Experimental groups consisted of 12 mice. Results

are presented as mean \pm SD Kruskal-Wallis with Dunn's post-hoc test

\section{Results of spontaneous activity examination}

Ketotifen administered alone did not change any parameter of spontaneous locomotor activity in mice (Table 2). VPA given alone significantly decreased animals' total and vertical activity, without affecting total distance (Table 2). When VPA was given with ketotifen, all aspects of spontaneous locomotor activity were significantly decreased (Table 2). When PB was given alone, only total distance was

Table 2. Influence of ketotifen (1 day treatment) on spontaneous locomotor activity in mice

\begin{tabular}{|l|c|c|c|}
\hline \multirow{2}{*}{ Drugs } & \multicolumn{2}{|c|}{ Horizontal activity } & \multirow{2}{*}{$\begin{array}{c}\text { Vertical } \\
\text { activity }\end{array}$} \\
\cline { 2 - 3 } & Total activity & $\begin{array}{c}\text { Total distance } \\
(\mathrm{cm})\end{array}$ & \\
\hline Control & $1244 \pm 65$ & $334 \pm 56$ & $155 \pm 16$ \\
Ketotifen [4.0] & $1184 \pm 132$ & $307 \pm 39$ & $196 \pm 31$ \\
CBZ [13.4] & $509 \pm 38 * *$ & $151 \pm 9 * *$ & $30 \pm 10^{* *}$ \\
CBZ [7.9] & $1287 \pm 104$ & $460 \pm 42$ & $266 \pm 51 *$ \\
CBZ [7.9]+Ketotifen [4.0] & $780 \pm 58 * * ; \# \#$ & $340 \pm 60$ & $103 \pm 16 * ; \# \#$ \\
VPA [254] & $637 \pm 65^{* *}$ & $442 \pm 46$ & $66 \pm 11^{* *}$ \\
VPA [234] & $588 \pm 67 * *$ & $478 \pm 53$ & $74 \pm 8^{* *}$ \\
VPA [234]+Ketotifen [4.0] & $213 \pm 26 * * ; \# \#$ & $276 \pm 30 \# \#$ & $64 \pm 6^{* *} ;$ \\
PB [24.9] & $1471 \pm 115$ & $709 \pm 85^{* *}$ & $209 \pm 36$ \\
PB [20,8] & $1821 \pm 221$ & $1208 \pm 89 * *$ & $124 \pm 15$ \\
PB [20.8]+Ketotifen [4.0] & $379 \pm 32 * * ; \# \#$ & $221 \pm 98 \# \#$ & $21 \pm 3 * * ; \# \#$ \\
DPH [8.2] & $595 \pm 59 * *$ & $175 \pm 18 *$ & $48 \pm 5^{* *}$ \\
DPH [7.8] & $1213 \pm 162$ & $483 \pm 141$ & $152 \pm 48$ \\
DPH [7.8]+Ketotifen [4.0] & $725 \pm 77$ & $314 \pm 55$ & $78 \pm 15$ \\
\hline * p<0.05; ** p<0.01; *** p<0.001 vs. vehicle; \# p<0.05; \#\# p<0.01; \\
\#\#\# p<0.001 vs. drug. Experimental groups consisted of 12 mice. Results \\
are presented as mean \pm SD Kruskal-Wallis with Dunn's post-hoc test
\end{tabular}

significantly increased. However, PB co-administered with ketotifen significantly impaired all three examined types of spontaneous locomotor activity. CBZ at a dose of $13.4 \mathrm{mg} / \mathrm{kg}$ also significantly lowered all parameters of spontaneous activity, whereas CBZ (dose $7.9 \mathrm{mg} / \mathrm{kg}$ ) given with ketotifen significantly decreased only total and vertical activity. DPH given alone (at a dose $8.2 \mathrm{mg} / \mathrm{kg}$ ) decreased mice spontaneous locomotor activity, however, when co-administered with ketotifen, all three parameters of locomotor activity were unaffected (Table 2).

Effects of ketotifen given alone or with AED on locomotor activity in mice after 7 days of administration

\section{Results of exploratory activity examination}

Ketotifen given alone significantly increased mice total and vertical activity, without changing total distance (Table 3). CBZ alone or combined with ketotifen did not significantly impair exploratory locomotor activity in mice. VPA alone or given with ketotifen significantly increased mice total distance, but not total and vertical activity (Table 3). PB alone or co-administered with ketotifen significantly increased all parameters of exploratory locomotor activity in mice (Table 3). DPH alone did not have any effect of exploratory activity in mice, but when given with ketotifen, all analyzed parameters significantly increased (Table 3 ).

Table 3. Influence of ketotifen (7 days treatment) on exploratory locomotor activity in mice

\begin{tabular}{|l|c|c|c|}
\hline \multirow{2}{*}{\multicolumn{1}{|c|}{ Drugs }} & \multicolumn{2}{c|}{ Horizontal activity } & \multirow{2}{*}{$\begin{array}{c}\text { Vertical } \\
\text { activity }\end{array}$} \\
\cline { 2 - 3 } & Total activity & $\begin{array}{c}\text { Total distance } \\
(\mathrm{cm})\end{array}$ & \\
\hline Control & $1561 \pm 105$ & $689 \pm 62$ & $232 \pm 32$ \\
Ketotifen [4.0] & $2570 \pm 349 *$ & $1073 \pm 202$ & $470 \pm 93 * *$ \\
CBZ [11] & $1877 \pm 317$ & $950 \pm 176$ & $255 \pm 60$ \\
CBZ [14.9] & $1785 \pm 262$ & $947 \pm 175$ & $240 \pm 51$ \\
CBZ [14.9]+Ketotifen [4.0] & $1870 \pm 457$ & $947 \pm 281$ & $345 \pm 94$ \\
VPA [256] & $1802 \pm 119$ & $1391 \pm 104 * *$ & $322 \pm 13$ \\
VPA [260] & $1510 \pm 113$ & $1486 \pm 120 * *$ & $309 \pm 18$ \\
VPA [260]+Ketotifen [4.0] & $2406 \pm 525$ & $1089 \pm 438 *$ & $325 \pm 45$ \\
PB [23.2] & $3093 \pm 260 * *$ & $2176 \pm 254 * *$ & $537 \pm 59 * *$ \\
PB [27.8] & $2982 \pm 155 * *$ & $2048 \pm 167 * *$ & $496 \pm 45 * *$ \\
PB [27.8]+Ketotifen [4.0] & $3808 \pm 298 * *$ & $2761 \pm 436 * *$ & $720 \pm 79 * *$ \\
DPH [10.0] & $1547 \pm 101$ & $734 \pm 24$ & $240 \pm 19$ \\
DPH [10.4] & $1528 \pm 113$ & $735 \pm 37$ & $215 \pm 29$ \\
DPH [10.4]+Ketotifen [4.0] $2180 \pm 101 * * ; \# \#$ & $1052 \pm 83 * * ; \#$ & $495 \pm 59 * * ; \#$ \\
* p<0.05; ** p<0.01; *** p<0.001 vs. vehicle; \# p<0.05; \#\# p<0.01; \\
\#\#\# p<0.001 vs. drug. Experimental groups consisted of 12 mice. Results \\
are presented as mean \pm SD Kruskal-Wallis with Dunn's post-hoc test
\end{tabular}

\section{Results of spontaneous activity examination}

Ketotifen alone did not affect spontaneous locomotor activity in mice (Table 4). CBZ administered alone did not change animal activity, however, in combination with

Table 4. Influence of ketotifen (7 days treatment) on spontaneous locomotor activity in mice

\begin{tabular}{|l|c|c|c|}
\hline \multirow{2}{*}{ Drugs } & \multicolumn{2}{c|}{ Horizontal activity } & \multirow{2}{*}{$\begin{array}{l}\text { Vertical } \\
\text { activity }\end{array}$} \\
\cline { 2 - 3 } & Total activity & $\begin{array}{c}\text { Total distance } \\
(\mathrm{cm})\end{array}$ & \\
\hline Control & $1244 \pm 65$ & $334 \pm 56$ & $155 \pm 16$ \\
Ketotifen [4.0] & $1462 \pm 313$ & $523 \pm 140$ & $310 \pm 81$ \\
CBZ [11] & $1246 \pm 95$ & $819 \pm 135$ & $293 \pm 66$ \\
CBZ [14.9] & $1889 \pm 228 *$ & $443 \pm 36 *$ & $250 \pm 52$ \\
CBZ [14.9]+Ketotifen [4.0] & $932 \pm 232 \#$ & $291 \pm 82 \#$ & $147 \pm 43$ \\
VPA [256] & $654 \pm 52 * *$ & $460 \pm 51$ & $74 \pm 12 * *$ \\
VPA [260] & $637 \pm 65^{* *}$ & $501 \pm 43$ & $82 \pm 7 * *$ \\
VPA [260]+Ketotifen [4.0] & $1483 \pm 246 \#$ & $1021 \pm 152^{* * ;} ;$ & $183 \pm 27 \# \#$ \\
PB [23.2] & $1865 \pm 195 *$ & $1254 \pm 73 * *$ & $141 \pm 17$ \\
PB [27.8] & $1453 \pm 102$ & $735 \pm 71 * *$ & $226 \pm 33$ \\
PB [27.8]+Ketotifen [4.0] & $2304 \pm 410 * *$ & $1209 \pm 325 *$ & $333 \pm 99$ \\
DPH [10.0] & $1269 \pm 147$ & $549 \pm 134$ & $169 \pm 43$ \\
DPH [10.4] & $1228 \pm 156$ & $502 \pm 136$ & $185 \pm 37$ \\
DPH [10.4]+Ketotifen [4.0] & $1453 \pm 160$ & $451 \pm 104$ & $301 \pm 77$ \\
\hline * p<0.05; $* *$ p<0.01; $* * *$ p<0.001 vs. vehicle; \# p<0.05; \#\# p<0.01; \\
\#\#\# p<0.001 vs. drug. Experimental groups consisted of 12 mice. Results \\
are presented as mean \pm SD Kruskal-Wallis with Dunn's post-hoc test
\end{tabular}


ketotifen, total and vertical activity in mice was significantly decreased (Table 4). VPA alone (dose $256 \mathrm{mg} / \mathrm{kg}$ and 260 $\mathrm{mg} / \mathrm{kg}$ ) decreased total and vertical activity, but when given with ketotifen an increase in all aspects of spontaneous activity was observed (Table 4). PB alone or co-administered with ketotifen significantly increased total horizontal activity and total distance in mice (Table 4). Neither DPH nor its combination with ketotifen affected spontaneous activity in mice after 7 days of administration (Table 4).

\section{DISCUSSION}

Co-administration of AEDs and $\mathrm{H}_{1}$-receptor antagonists can complicate epilepsy control, and an increase in the frequency of seizure attacks was reported after using some of first generation $\mathrm{H}_{1}$-receptor antagonists, such as chlorpheniramine, diphenhydramine, pheniramine and pyribenzamine. Newer generation of $\mathrm{H}_{1}$-receptor antagonists, such as astemizole, cetirizine, fexofenadine, loratadine and terfenadine had also shown similar results [24-26]. Indeed, the United States Agency Food and Drug Administration (FDA) has provided data according to which seizures caused by cetirizine, fexofenadine and loratadine were responsible for $2.5 \%, 3.5 \%$ and $2.1 \%$ of the total adverse effects caused by these drugs, respectively.

The results of our study have shown how diversely ketotifen can influence locomotor activity in mice when co-administered with AEDs. In our acute experiments, ketotifen was shown to increase animal exploratory activity without changing their spontaneous behaviors. However coadministration of AEDs significantly reduced mice exploratory activity. Similarly, after 7 days of administration, ketotifen significantly increased mice exploratory activity, not affecting their spontaneous activity. What is interesting, co-administration of VPA, PB and DPH increased animal exploratory activity, even when they did not have any effect alone. Different effects were also observed when spontaneous animal activity was analyzed. In combination with ketotifen, CBZ was shown to decrease animal activity, whereas co-administration of ketotifen with VPA or PB increased animal spontaneous activity. Our results are especially important in comparison with previous studies analyzing the antiepileptic potential of ketotifen and its interactions with AEDs in various seizure models.

In a previous study, combinations of similar drugs and their influence on median effective dose $\left(\mathrm{ED}_{50}\right)$, median toxic dose $\left(\mathrm{TD}_{50}\right)$ and median current strength value $\left(\mathrm{CS}_{50}\right)$ against MES in mice were examined [17]. It is especially worth mentioning that ketotifen intensified convulsions in animals from the aforementioned study and lowered the electroconvulsive threshold. In our study, ketotifen reduced the anticonvulsant activity of CBZ when given for 7 days. In contrast, the anticonvulsant activity of $\mathrm{CBZ}$ and $\mathrm{PB}$ was elevated in the acute study.

Another study that examined a $\mathrm{H}_{1}$-receptor antagonist, this time, astemizole, showed impaired movement and horizontal distance when given with CBZ in spontaneous activity examination [27]. Moreover, the same study showed decreased movement in mice treated with astemizole and VPA in spontaneous activity examination. The analysis of exploratory activity draws attention to decreased vertical movement in the case of both drugs, VPA and CBZ when administered with this $\mathrm{H}_{1}$-receptor antagonist.

The influence of histamine receptors on monoamine- and cholinergic systems plays important role in understanding the correlation between antihistamine drugs and locomotor activity regulation in animals. Stimulation of histamine receptors leads to parasympathetic nervous system stimulation. As it is currently known, promethazine, also a $\mathrm{H}_{1}$-receptor antagonist, and one of the tricyclic analogues like ketotifen, blocks receptors involved in the reuptake of serotonin and acetylcholine. It also stimulates a-adrenergic receptors. A study performed by Tuomisto et al. showed that the $\mathrm{H}_{1}$-receptor antagonist, mepyramine inhibited monoamine uptake. Tuomisto et al. also demonstrated that histamine took part in the process of monoamine release [28].

It should be noted that $\mathrm{H}_{3}$-receptor agonists lower the level of acetylcholine secretion in brain and peripheral nerves. Studies have shown that thioperamide in a dose of $20 \mathrm{mg} / \mathrm{kg}$ administered alongside with zolantidine ( $\mathrm{H}_{2}$-receptor antagonist) increased the level of choline in different brain regions. The combination of both drugs (zolantidine as a pretreatment) improved scopolamine-induced learning deficits [29]. Moreover, it was reported in preclinical models that $\mathrm{H}_{3}$-receptor antagonists take part in processes of enhancing cognition and influence neurotransmission, especially cholinergic. The improvement in cognitive performance was shown when ABT-239 $\left(\mathrm{H}_{3}\right.$-receptor antagonist) and donepezil (acetylcholinesterase inhibitor) were administered systematically [30]. Another study revealed that $\mathrm{H}_{3}$-receptor antagonists may have positive influence on the course of Alzheimer's disease [31]. According to Serafim et al., $\mathrm{H}_{1}$-receptor antagonists are involved in the acquisition of emotional memory and anxiety-like behavior in mice [32]. However, another study showed that $\mathrm{H}_{1}$ receptors in the amygdala do not take part in inducing anxietyrelated behaviors [33].

The presented study has indicated that the combination of ketotifen and certain AEDs have diverse influences on mice locomotor activity - depending on duration of administration of drugs, type of movement and forms of animal activity. The increase in exploratory animal activity caused by ketotifen alone should be highlighted. Moreover, co-administration with some AEDs may stimulate this effect, potentially aggravating anxiety-like behaviors.

After analyzing the aforementioned data, some outliers can be observed. Significant reduction of locomotor activity was noted in the acute study (drugs given as a single dose) of exploratory activity and this came about most strikingly after co-administration of VPA and ketotifen. Moreover, in the acute study of spontaneous activity in mice, a significant reduction of most locomotor activity parameters compared to control group came about when ketotifen was given with CBZ, VPA or PB. In the same study, vertical activity was decreased in a group that received $\mathrm{PB}$ or $\mathrm{DPH}$ with ketotifen. Contrary to other tested AEDs, PB alone or co-administered with ketotifen significantly increased all three locomotor parameters in a 7-day study of exploratory activity. Increased total activity and total distance were also observed in a 7-day study of spontaneous activity. 
Our study has shown that $\mathrm{H}_{1}$-receptor antagonist such as ketotifen should be prescribed with caution to patients with epilepsy. Due to different interactions with various AEDs, each drug should be carefully analyzed in the context of possible locomotor impairments. Potential clinical aspects of results presented in this study need future analyses.

\section{ACKNOWLEDGEMENTS}

This study was supported by the State Committee for Scientific Research (KBN) grant No 3PO5F03523.

\section{DISCLOSURES}

There are no relevant disclosures or conflicts of interest

\section{ORCID iDs}

Izabela Zakrocka (Dhttps://orcid.org/0000-0001-5251-7763 Katarzyna Świąder (1)https://orcid.org/0000-0002-9214-927X Mariusz Świąder (1) https://orcid.org/0000-0001-8093-1654

\section{REFERENCE}

1. Beghi E, Giussani G, Sander JW. The natural history and prognosis of epilepsy. Epileptic Disord. 2015;17(3):243-53.

2. Sander JW. The epidemiology of epilepsy rivisited. Curr Opin Neurol. 2008;16:165-70.

3. Berghi E. Prognosis of first seizure. In: Jallon P, Berg AT, Dulac O, Hauser WA. Prognosis of epilepsies. Montrouge: JohnLibbey; 2003:21-8.

4. Pavlova M. Sudden unexpected death in epilepsy: Assessing the risk factors. Neurology. 2020 28;94(4):e436-e438.

5. Manford M. Recent advances in epilepsy. J Neurol. 2017;264(8): 1811-24.

6. Haas HL, Sergeeva OA, Selbach O. Histamine in the nervous system. Physiol Rev. 2008;88(3):1183-241.

7. $\mathrm{Hu} \mathrm{W}$, Chen $\mathrm{Z}$. The roles of histamine and its receptor ligands in central nervous system disorders: An update. Pharmacol Ther. 2017;175:116-32.

8. Schlicker E, Kathmann M. Role of the histamine $\mathrm{H} 3$ receptor in the central nervous system. Handb Exp Pharmacol. 2017;241:277-99.

9. Lebois EP, Jones CK, Lindsley CW. The evolution of histamine $\mathrm{H}_{3}$ antagonists/inverse agonists. Curr Top Med Chem. 2011;11(6):648-60.

10. Sakai N, Onodera K, Maeyama K, Yanai K, Watanabe T. Effects of thioperamide, a histamine $\mathrm{H} 3$ receptor antagonist, on locomotor activity and brain histamine content in mast cell-deficient $\mathrm{W} / \mathrm{Wv}$ mice. Life Sci. 1991;48(25):2397-404.

11. Mohsen A, Yoshikawa T, Miura Y, Nakamura T, Naganuma F, Shibuya K, et al. Mechanism of the histamine H(3) receptormediated increase in exploratory locomotor activity and anxiety-like behaviours in mice. Neuropharmacol. 2014;81:188-94.

12. Gerald MC, Richter NA. Studies on the effects of histaminergic agents on seizure susceptibility in mice. Psychopharmacol. 1976; 46(3):277-82.

13. Tuomisto $\mathrm{L}$, Tacke $\mathrm{U}$. Is histamine an anticonvulsive inhibitory transmitter? Neuropharmacol. 1986;25(8):955-8.

14. Yokoyama H, Onodera K, Maeyama K, Yanai K, Iinuma K, Tuomisto L, Watanabe T. Histamine levels and clonic convulsions of electrically-induced seizure in mice: the effects of alphafluoromethylhistidine and metoprine. Naunyn Schmiedebergs Arch Pharmacol. 1992;346(1):40-5.
15. Yokoyama $\mathrm{H}$, Onodera $\mathrm{K}$, Iinuma $\mathrm{K}$, Watanabe T. Effect of thioperamide, a histamine $\mathrm{H} 3$ receptor antagonist, on electrically induced convulsions in mice. Eur J Pharmacol. 1993;234(1):129-33.

16. Wyngaarden JB, Seevers MH. The toxic effects of antihistaminic drugs. J Am Med Assoc. 1951;145(5):277-82.

17. Churchill JA, Gammon GD. The effect of antihistaminic drugs on convulsive seizures. J Am Med Assoc. 1949;141(1):18-21.

18. Yokoyama H, Onodera K, Iinuma K, Watanabe T. 2-Thiazolylethylamine, a selective histamine $\mathrm{H} 1$ agonist, decreases seizure susceptibility in mice. Pharmacol Biochem Behav. 1994;47(3):503-7.

19. Yasuhara A, Ochi A, Harada Y, Kobayashi Y. Infantile spasms associated with a histamine H1 antagonist. Neuropediatrics. 1998; 29(6):320-1.

20. Yokoyama H, Iinuma K, Yanai K, Watanabe T, Sakurai E, Onodera K. Proconvulsant effect of ketotifen, a histamine $\mathrm{H} 1$ antagonist, confirmed by the use of $\mathrm{d}$-chlorpheniramine with monitoring electroencephalography. Methods Find Exp Clin Pharmacol. 1993; 15(3):183-8.

21. Świąder M, Wielosz M, Czuczwar SJ. Influence of antazoline and ketotifen on the anticonvulsant activity of conventional antiepileptics against maximal electroshock in mice. Eur Neuropsychopharmacol. 2004;14(4):307-18.

22. Świąder M, Wielosz M, Czuczwar SJ. Interaction of astemizole, an $\mathrm{H} 1$ receptor antagonist, with conventional antiepileptic drugs in mice. Pharmacol Biochem Behav. 2003;76(1):169-78.

23. Luszczki JJ, Andres MM, Swiader MJ. Effect of lamotrigine combined with felbamate on the horizontal (ambulatory) activity in mice. Ann Univ Mariae Curie Sklodowska Med. 2004;59(2):235-40.

24. Ten Eick AP, Blumer JL, Reed MD. Safety of antihistamines in children. Drug Safety. 2001;24(2):119-147.

25. Blain PG, Lane RJM. Neurological disorders. In: DM. Davies, RE. Ferner, H. De Glanville (eds). Davies's Textbook of Adverse Drug Reactions. 5th ed. London: Chapman and Hall Medical; 1998:591-3.

26. Murphy K, Delanty N. Drug-induced seizures: general principles in assessment, management and prevention. CNS Drugs, 2000;14(2): 135-46.

27. Świąder M, Świąder K. Influence of astemizole, an $\mathrm{H} 1$ receptor antagonist, on the locomotors activity of carbamazepine and valproate in mice. Curr Issues Pharm Med Sci. 2012;25(2):173-5.

28. Tuomisto J, Tuomisto L. Effects of histamine and histamine antagonists on the uptake and release of catecholamines and 5-HT in brain synaptosomes. Med Biol. 1980;58(1):33-7.

29. Miyazaki S, Imaizumi M, Onodera K. Effects of thioperamide on the cholinergic system and the step-throuhg passive avoidance test in mice. Methods Find Exp Clin Pharmacol. 1995;17(10):653-8.

30. Provensi G, Costa A, Passani MB, Blandina P. Donepezil, an acetylcholine esterase inhibitor, and ABT-239, a histamine $\mathrm{H} 3$ receptor antagonist/inverse agonist, require the integrity of brain histamine system to exert biochemical and procognitive effects in the mouse. Neuropharmacol. 2016;109:139-47.

31. Bitner RS, Markosyan S, Nikkel AL, Brioni JD. In-vivo histamine $\mathrm{H} 3$ receptor antagonism activates cellular signaling suggestive of symptomatic and disease modifying efficacy in Alzheimer's disease. Neuropharmacol. 2011;60(2-3):460-6.

32. Serafim KR, Kishi MS, Canto-de-Souza A, Mattioli R. $\mathrm{H}_{1}$ but not $\mathrm{H}_{2}$ histamine antagonist receptors mediate anxiety-related behaviors and emotional memory deficit in mice subjected to elevated plusmaze testing. Braz J Med Biol Res. 2013;46(5):440-6.

33. Serafim KR, Gianlorenço AC, Daher FP, Mattioli R. H1-histamine receptors in the amygdala are involved in emotional memory but do not mediate anxiety-related behaviors in mice submitted to EPM testing. Brain Res Bull. 2012;89(1-2):1-7. 